\title{
Eomesodermin Homolog
}

National Cancer Institute

\section{Source}

National Cancer Institute. Eomesodermin Homolog. NCI Thesaurus. Code C102929.

Eomesodermin homolog ( $686 \mathrm{aa}, \sim 73 \mathrm{kDa}$ ) is encoded by the human EOMES gene. This protein plays a role in transcriptional activation of genes involved in trophoblast differentiation, gastrulation, and brain development. 